\title{
The Potential of Non-Ionic Surfactants for Extraction of Lactic Acid from Aqueous Solution
}

\author{
Remil Aguda 1,2, Shayla LeBoeuf ${ }^{1,2}$, Cody Stelly 1,2, Samantha Bonilla ${ }^{1,2}$, Brandon LeBlanc 1,2, \\ William Holmes ${ }^{2}$, Rafael Hernandez ${ }^{1,2}$, Mark E. Zappi ${ }^{1,2}$ and Emmanuel D. Revellame ${ }^{2,3, *(\text { ) }}$ \\ 1 Department of Chemical Engineering, University of Louisiana at Lafayette, Lafayette, LA 70504, USA; \\ remil.aguda1@louisiana.edu (R.A.); sal2217@louisiana.edu (S.L.); cody.stelly1@louisiana.edu (C.S.); \\ sab7059@louisiana.edu (S.B.); brandon.leblanc1@louisiana.edu (B.L.); \\ rhernandez@louisiana.edu (R.H.); zappi@louisiana.edu (M.E.Z.) \\ 2 The Energy Institute of Louisiana, University of Louisiana at Lafayette, Lafayette, LA 70504, USA; \\ bill.holmes@louisiana.edu \\ 3 Department of Industrial Technology, University of Louisiana at Lafayette, Lafayette, LA 70504, USA \\ * Correspondence: erevellame@louisiana.edu; Tel.: +1-337-482-6983
}

Received: 27 June 2020; Accepted: 29 July 2020; Published: 31 July 2020

Featured Application: This work could serve as the theoretical basis for the advancement of extractive short-chain carboxylic acid fermentation through solvent extraction.

\begin{abstract}
Lactic acid, an important commodity chemical for various applications, is mainly produced through fermentation. In this study, the potential of non-ionic surfactants (an alcohol ethoxylate (AE) and two alcohol alkoxylates (AAs)) as solvents for the extraction of lactic acid from aqueous solutions is reported for the first time. Ternary mixtures containing lactic acid, water, and surfactants were prepared for the assessment. The results indicated that for all the systems, the water-surfactant binary pair exhibits partial immiscibility. Furthermore, the results suggested that with respect to the size of the two-phase region and stability of phases developed, the $\mathrm{AE}$ is the suitable solvent for the targeted extraction process. Thus, tie-lines for the system lactic acid + water + AE were then determined to establish the phase diagram of the system at $308.15 \mathrm{~K}$. From the tie-lines, distribution coefficients and separation factors were estimated, which indicated that a compromise between the size and number of extraction units is necessary if $\mathrm{AE}$ is to be used as a solvent for lactic acid extraction. The extraction efficiency was estimated to be only about $37-48 \%$. Nevertheless, the biodegradability and non-toxicity of $\mathrm{AE}$ makes it a viable solvent for the development of the extractive lactic acid fermentation process.
\end{abstract}

Keywords: alcohol ethoxylate; alcohol propoxylate; phase equilibria; extractive fermentation; pseudo-ternary system

\section{Introduction}

Lactic acid is a compound with a unique characteristic of having both hydroxyl and carboxylic acid groups, making it a commonly used precursor for wide ranging applications in the cosmetic, pharmaceutical, polymer, textile, food, and chemical industries. Some of the known applications of lactic acid include: (1) dehydration to acrylic acid; (2) polymerization to poly-lactic acid (PLA); and (3) condensation to 2,3-pentanedione [1-3]. Lactic acid is also often utilized as an alternative raw material for production of commodity chemicals such as propionic acid, pyruvic acid, and propylene glycol [1]. Lactic acid and lactates are considered to have direct effect on dietary mineral supply and are used for athletes training, metabolic rate modulation, weight management, lowering the glycemic index of bread, and improved mineral supplementation in nutritional formulas for infants and people 
using proton inhibitors [4]. These applications drive the demand for lactic acid, with an annual global capacity estimated to exceed $1960 \mathrm{kt}$ by 2020 [5].

Majority ( $90 \%)$ of lactic acid currently available in the market is produced through fermentation with glucose, sucrose (from cane and beet), whey (containing lactose and maltose), and dextrose (from hydrolyzed starch) as commonly used carbohydrates for commercial applications. The remaining lactic acid in the market is produced through chemical synthesis from acetaldehyde and hydrogen cyanide $[1,2,6]$. With respect to feedstock flexibility, the fermentation route is preferred and can use substrates based on local or regional availability. In addition, studies on lactic acid production from lignocellulosic biomass are currently being pursued, which could widen the geographical regions for lactic acid fermentation [5,7-9].

Lactic acid fermentation is typically carried out in a batch mode of operation. During the fermentation, the $\mathrm{pH}$ of the system decreases as more and more lactic acid is produced. The decrease in $\mathrm{pH}$ causes microbial inhibition that eventually shuts down the process. The usual practice to overcome this limitation is to add a base (i.e., calcium hydroxide) during the fermentation to neutralize and partially precipitate the acid as calcium lactate. At the conclusion of the batch run, more calcium hydroxide is added to precipitate majority of the lactic acid. The precipitates are then filtered and treated with sulfuric acid to recover the lactic acid. Despite its effectiveness, this downstream process for lactic acid purification utilizes large quantity of unrecoverable calcium hydroxide and sulfuric acid that end up as solid wastes (i.e., calcium sulfate) which require treatment before disposal $[1,6,10]$.

To improve lactic acid productivity, genetic and metabolic engineering [11-14], fed-batch fermentation mode [15,16], and continuous fermentation [17] can be exploited. Among these options, the continuous fermentation offers the possibility of applying an extractive fermentation strategy to remove or recover the lactic acid as it is produced during the process thereby eliminating the $\mathrm{pH}$-induced microbial inhibition [1]. Extractive fermentation includes liquid-liquid extraction (sometimes referred to as biphasic fermentation or phase-partitioning bioreactor) [10,18], adsorption $[19,20]$, and membrane separation (e.g., electrodialysis) [21-23]. The liquid-liquid extraction is limited by solvent availability, while both adsorption and membrane separation are limited by biofouling during the fermentation process.

Solvents that have been evaluated for extractive fermentation through liquid-liquid extraction include long chain aliphatic tertiary amines (e.g., trioctylamine, alamine), long chain alcohols (e.g., octanol, decanol), and their mixtures [1,24]. Despite their high extraction efficiency, as indicated by their distribution coefficients, these solvents are not suitable for extractive fermentation due to their microbial toxicity, making them less prone to biodegradation, which could pose tremendous environmental burden [24]. Thus, there is a need to find an alternative solvent for lactic acid extractive fermentation.

According to Brink and Tramper [25], solvents with low polarity and high molecular weight are expected to have the least toxicity. Non-ionic surfactants exhibit these two characteristics, and they are known to be easily amenable to biological treatment $[26,27]$, which could minimize the environmental challenges of extractive fermentation at industrial scale. Belgodere et al. [28] found that non-ionic surfactant, specifically a mixture of $\mathrm{C}_{10-16}$ alcohol ethoxylates, can be utilized for extraction of short chain carboxylic acids (i.e., acetic, propionic, and butyric acids) from aqueous solutions. They also concluded that the extraction effectiveness increases as the length of the carboxylic acid molecule increases due to the increase in hydrophobicity.

This study was conducted to evaluate the potential of non-ionic surfactant as solvent for extractive lactic acid fermentation. Non-ionic surfactants, especially those that belong to the alcohol ethoxylate group as well as alcohol ethoxylate/propoxylate copolymer (or alcohol alkoxylates) are non-toxic to microorganisms and biodegradable $[26,27,29-31]$. Their water miscibility can also be modified by changing the length of the alcohol component and the number of ethoxylate units in their molecule [32]. Three non-ionic surfactants were initially assessed qualitatively with respect to their ability to produce biphasic mixtures with water and lactic acid. Based on the results, the ternary phase diagram for lactic acid + water + non-ionic surfactant was established at $308.15 \mathrm{~K}$ (the commonly used temperature for 
mesophilic lactic acid fermentation). This was done to determine the extraction effectiveness of the surfactant as indicated by the distribution coefficients and separation factors.

\section{Experimental Section}

\subsection{Materials}

Table 1 shows purities and some properties of the materials used in this study. These materials were used as received from the supplier.

Table 1. Materials used in the phase equilibrium study.

\begin{tabular}{cccc}
\hline Chemical Name & IUPAC Name & CAS No. & Mass Fraction ${ }^{\mathbf{1}}$ \\
\hline Alcohol Ethoxylates (AE) & Alcohols, $C_{10-16}$, ethoxylated & $68002-97-1$ & $>0.99^{2}$ \\
Alcohol Alkoxylates (AA1) & Alcohols, $C_{10-12}$ ethoxylated propoxylated & $68154-97-2$ & 0.9 to $^{2} .00^{3}$ \\
Alcohol Alkoxylates (AA2) & Alcohols, $C_{12-13}$ ethoxylated propoxylated & $70750-27-5$ & $1.00^{3}$ \\
Lactic acid-water solution & - & - & 0.85 \\
Lactic acid & 2-hydroxypropanoic acid & $79-33-4$ & (lactic acid) \\
Water & Oxidane & $7732-18-5$ & 0.999 \\
\hline
\end{tabular}

${ }^{1}$ Supplier provided properties. ${ }^{2}$ The purity of the sample used in this study was previously determined by GC-MS [28]. ${ }^{3}$ The actual purity of the surfactant was not determined since no quantitation was performed for ternary systems involving the surfactant.

It should be noted that the phase separation in this work was intended to be due to surfactant immiscibility in water alone. For this, the Hydrophile-Lipophile Balance (HLB) of the surfactant was the main property considered. HLB is a measure of relative hydrophobicity of surfactants and rated from $0-20$, with those with HLB $<9$ considered to be lipophilic [33]. The surfactants used in this study have HLB of 6.3 for AE, and 6.0 for both AA1 and AA2 as provided by the manufacturer.

\subsection{Equilibrium Sample Preparation and Procedure}

Mixtures (at least $5 \mathrm{~g}$ ) of lactic acid, water, and non-ionic surfactant were prepared in conical glass test tubes. For mixtures that required $\leq 70 \mathrm{wt} . \%$ of lactic acid, the lactic acid-water solution $(85 \mathrm{wt} . \%$ purity) was used for the preparation. On the other hand, mixtures with high lactic acid concentration (>70 wt.\%) were prepared using pure lactic acid (99.9 wt.\% purity). The prepared mixtures were vortex-mixed for $1 \mathrm{~min}$ and were incubated at $308.15 \mathrm{~K}$ using a Fisher Scientific incubator (Pittsburgh, PA, USA). This is the temperature commonly used for mesophilic lactic acid fermentation. The mixtures were qualitatively (visually) monitored for phase formation/separation for a period of at least 1 month, after which, the mixtures that produced significant amount of the two phases formed were sampled for phase composition determination (see Section 2.4).

\subsection{Equilibrium Time Determination}

After 1 month of equilibration, a set of lactic acid, water and non-ionic surfactant mixtures with similar composition that fall inside the qualitatively determined two-phase region were prepared. The mixtures were equilibrated at $308.15 \mathrm{~K}$ with an assigned incubation time. At the completion of the assigned time for each mixture, the phases formed were sampled and analyzed (please see Section 2.4) to determine phase composition. Consequently, the obtained compositions were plotted against the assigned time to determine the time for the system to reach equilibrium.

\subsection{Sample Analyses}

Determination of surfactant and lactic acid composition was conducted using a HP1100 LC system (Agilent, Santa Clara, CA, USA) equipped with an Acclaim Surfactant Plus column (Thermo Scientific North, Waltham, MA, USA). Solvents A (Acetonitrile) and B (0.05 vol.\% triflouroacetic acid aqueous 
solution) at $1.35 \mathrm{~mL} / \mathrm{min}$ were used for a gradient elution as follows: $100 \% \mathrm{~A}$ to $\mathrm{A} / \mathrm{B}(60 / 40)$ in $5 \mathrm{~min}$ then held for $1 \mathrm{~min}$. Surfactant quantitation was conducted using an Evaporative Light Scattering Detector (ELSD) with a drift tube temperature of $338.15 \mathrm{~K}\left(65^{\circ} \mathrm{C}\right)$ and spray chamber at $293.15 \mathrm{~K}$ $\left(20^{\circ} \mathrm{C}\right)$, while the lactic acid concentration was measured using a diode array detector (DAD) at $210 \mathrm{~nm}$. The water content of the samples was measured using a CS20 Karl Fischer titrator (Mettler Toledo, Columbus, $\mathrm{OH}, \mathrm{USA}$ ). The absorbance of the surfactant-rich layers were also measured using a DU 800 Beckman Coulter Spectrophotometer at $600 \mathrm{~nm}$. This was based on the method utilized by Rang and Miller [34] on their work on the stability of surfactant mixtures as a function of turbidity.

\section{Results and Discussion}

\subsection{Qualitative Liquid-Liquid Equilibria}

Due to the presence of both carboxylic and alcohol functional groups in the lactic acid molecule, it is anticipated that the ternary systems considered in this study will behave differently compared to the linear aliphatic short chain carboxylic acids. Thus, the initial phase of the study focused on observing the behavior (i.e., ability to form two-phase region) of the ternary systems under study through visual observation. This initial assessment determines the suitability of the non-ionic surfactant for the targeted extractive separation process.

The qualitative phase equilibrium observations were conducted for at least a month. Based on the observations, the two-phase region or phase envelope was estimated for each ternary system and the results are presented in Figure 1. The suitability of the surfactant as solvent for lactic acid extraction can be initially assessed by the type of the ternary system. The results indicated that all the systems studied belong to the Type 1 Treybal classification of ternary systems [35], with the water-surfactant binary pair exhibiting partial immiscibility. It is important to note that all the surfactants used in this study are mixtures containing different lengths of the alcohol component. However, the surfactants were treated as a single compound and thus, all the systems studied can be considered as pseudo-ternary systems.

The results showed that AE and AA1 (Figure 1a, b) are the two surfactants that could possibly be used for the extraction of lactic acid from aqueous mixtures based on the size of the estimated phase envelope. The size of this two-phase region dictates the region where the liquid-liquid extraction can be strategized and consequently determines operational parameters (e.g., amount of solvent needed for extraction and the number of extraction stages needed). As Figure 1c shows, AA2 is not applicable for the targeted lactic acid separation process due to a very small phase envelope.

It is well established that water-nonionic surfactant binary systems at temperatures between 273.15-373.15 K exhibit a closed loop miscibility gap (that typically has a vertical oblong shape) with a lower and upper critical point [36]. The lower critical point is also known as the cloud point which is the temperature at which the water-miscible surfactant comes out of the solution as a result of decreased H-bonding between water and surfactant molecules [37]. The size of this miscibility gap with respect to concentration is represented by the length of the water-surfactant binary tie-lines in Figure 1 . According to the manufacturers, the surfactants used in this study have cloud points of $327.15 \mathrm{~K}, 288.15$ $\mathrm{K}$, and $290.15 \mathrm{~K}$ for AE, AA1, and AA2, respectively. The differences can be attributed to the alkyl chain length of the surfactants, which has direct correlation with cloud point (i.e., cloud point increases with the alkyl chain length) [38]. Accordingly, these suggest that at $308.15 \mathrm{~K}$, the phase envelope of the AE ternary system can be attributed mainly to HLB. Conversely, the phase envelope for the AA ternary systems was due to both the HLB and cloud point of the surfactants.

The shorter length of the miscibility gap (thus smaller phase envelope) for AA2 could indicate that the system has either an intrinsically narrower loop compared to the other surfactants or the temperature of $308.15 \mathrm{~K}$ is close to the upper critical temperature of the loop. For the latter case, the length of the miscibility gap could be increased by decreasing the extraction temperature. Consequently, this could increase the size of the phase envelope of the system that could lead to a better extraction process. 
However, since the focus of this work is on the extractive fermentation of lactic acid at $308.15 \mathrm{~K}, \mathrm{AA} 2$ cannot be used as solvent due to the small phase envelope of its ternary system.

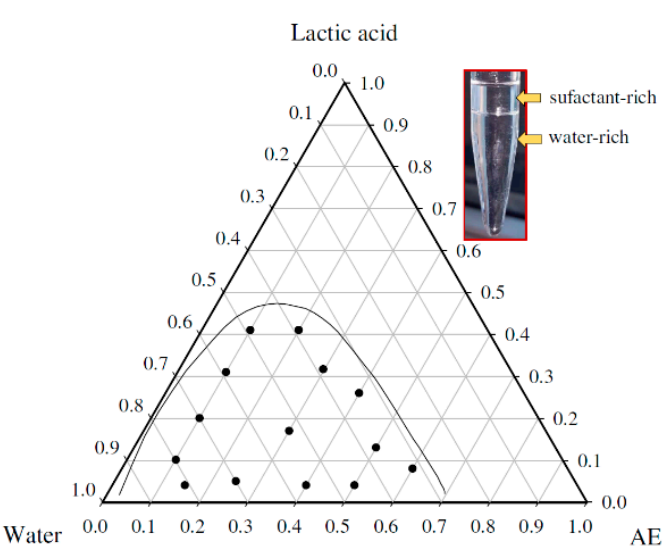

(a)

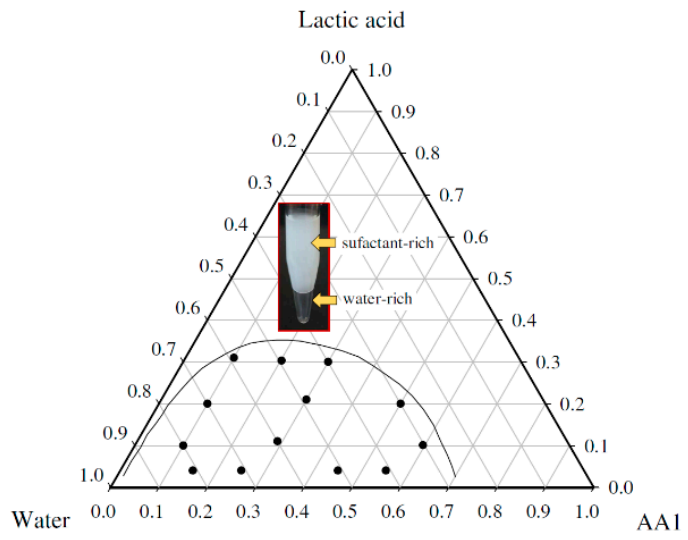

(b)

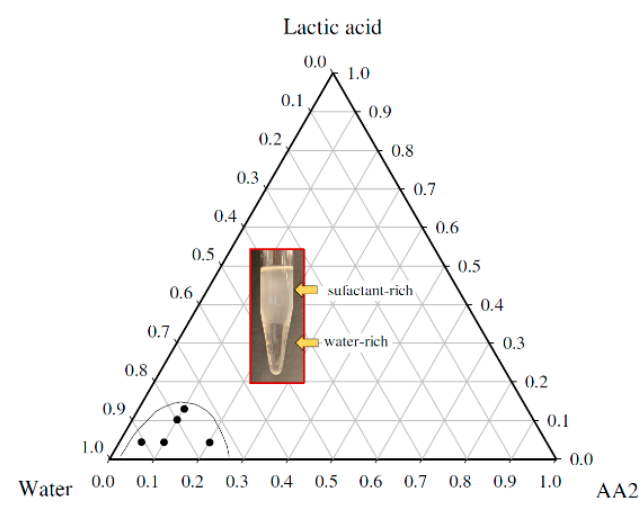

(c)

Figure 1. Estimated binodal curve for the system lactic acid + water + surfactant at $T=308.15 \mathrm{~K}$ and $P=0.1 \mathrm{MPa}$ (atmospheric pressure): (a) AE; (b) AA1; (c) AA2.

The qualitative study of the phase equilibria of the three systems also showed that the surfactant-rich layers of AA surfactants (Figure $1 \mathrm{~b}, \mathrm{c}$ ) exhibited turbidity that was not observed in the mixtures of the AE surfactant. This turbidity can be expected since the temperature of the mixtures was above the cloud point of the AA surfactants. Weak acids, such as lactic acid, are known to increase the cloud point when added to nonionic surfactant-water mixtures, i.e., weak acids act as salting-in agents [39]. The turbidity of the two systems, however, indicate that the addition of lactic acid was not enough to significantly raise the cloud point of the AA ternary systems.

In emulsion systems, turbidity is an indication of system instability [34]. Turbidity increases with an increase in emulsion size. However, since emulsion size is inversely related to emulsion stability (i.e., stability increases as emulsion size decreases), it follows that turbid emulsions are less stable than the clearer ones. The top layers (surfactant-rich phase) of the ternary systems have absorbances (at $600 \mathrm{~nm}$ ) of $0.1440,1.3562$, and 1.7160 for AE, AA1, and AA2, respectively. Since absorbance is directly proportional to turbidity [40], it follows that the top layers of the AA ternary systems are less stable than that of the AE system. Thus, despite the relatively wide two-phase region of the AA1 ternary system, the results suggest its unsuitability as a solvent for the envisioned extraction process. Thus, among the surfactants evaluated, only AE was deemed suitable as a solvent and was subjected to further experimentations. 


\subsection{Phase Separation or Equilibrium Time}

To ensure that phase equilibrium was achieved within the period ( $\geq 1$ month) of incubation, a set of mixtures of lactic acid, water, and $\mathrm{AE}$ with the same composition (within the two-phase region) was prepared and used to determine the system equilibrium time at $308.15 \mathrm{~K}$. The time to reach equilibrium is critical to the establishment of the phase diagram, for the obvious reason that the system must be at equilibrium during phase composition measurements. Operationally, if the solvent is to be used for liquid-liquid extraction, the equilibrium time determines the settling time or retention time needed for the separation process.

The results (Figure 2) indicated that the lactic acid + water + AE system attained equilibrium after $168 \mathrm{~h}$ ( 7 days) of incubation at $308.15 \mathrm{~K}$. This suggests that 1 month of incubation was more than enough for the establishment of the phase diagram. However, 7 days is not a very ideal extraction retention time, especially if the process is to be conducted in batch or semi-batch mode. Nevertheless, the results also indicated that the system was within $80 \%$ of equilibrium after $3.5 \mathrm{~h}$ of incubation. This is a more reasonable operational retention time for lactic acid extraction that could be applied for an actual separation process.

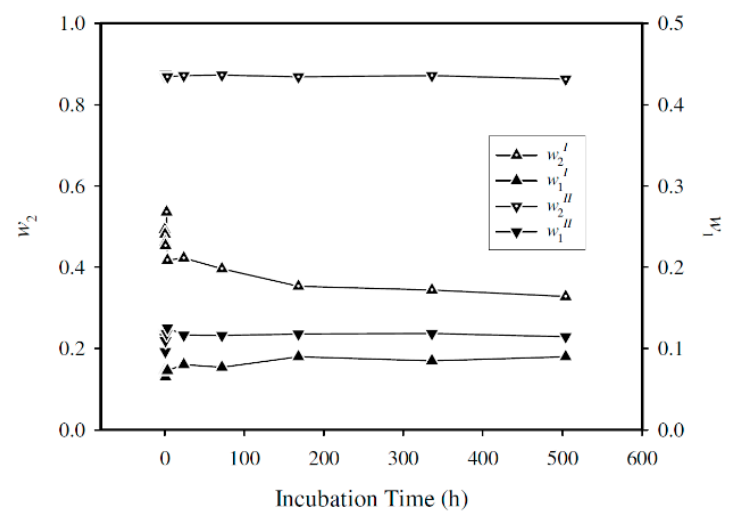

Figure 2. Concentration of phases formed as a function of incubation time for the system lactic acid (1) + water (2) $+\mathrm{AE}(3)$ at $T=308.15 \mathrm{~K}$ and $P=0.1 \mathrm{MPa}$ (atmospheric pressure).

\subsection{Liquid-Liquid Equilibrium (LLE) Data}

The experimental LLE for the pseudo-ternary system containing lactic acid, water, and AE at $308.15 \mathrm{~K}$ are presented in Figure 3 and Table 2. The obtained tie-lines indicate that lactic acid has preferential attraction or miscibility to the aqueous phase. This suggests an ineffective extraction process if the AE surfactant is to be used as a lactic acid extraction solvent. As previously mentioned, the studied temperature $(308.15 \mathrm{~K})$ is lower than the cloud point of the AE surfactant. Thus, the two-phase region of its ternary system can be accounted solely on its HLB or water miscibility (i.e., the system is not dictated by the closed loop miscibility gap). Since the water miscibility of nonionic surfactants decreases with temperature [36], raising the extraction temperature could possibly improve the effectiveness of the extraction. Nevertheless, this can possibly be explored for the extraction of other metabolites or for extraction configuration other than extractive fermentation. As for the case of this work, the AE surfactant had to be assessed at the temperature $(308.15 \mathrm{~K})$, as dictated by the target application. 


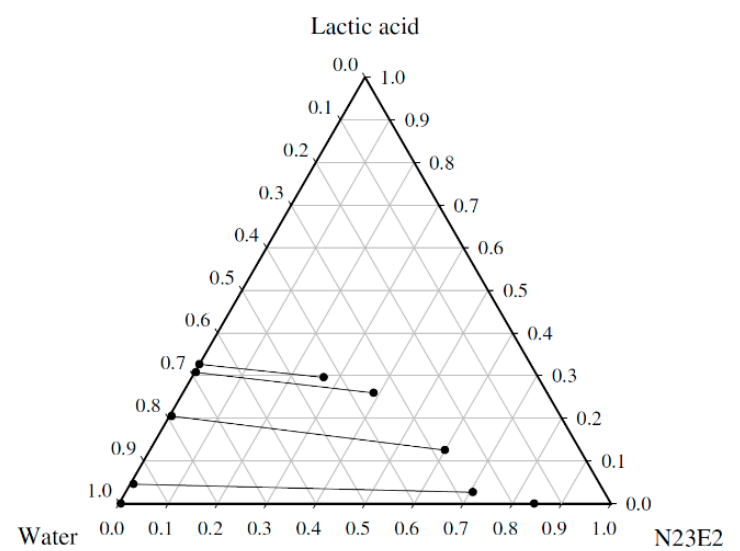

Figure 3. Experimental ternary phase liquid-liquid equilibria (tie-lines) for lactic acid + water + alcohol ethoxylate (AE) at $T=308.15 \mathrm{~K}$ and $P=0.1 \mathrm{MPa}$ (atmospheric pressure).

Table 2. Experimental tie-line data in mass fraction, $w$, for the ternary system containing lactic acid (1), water (2), and $\mathrm{AE} \mathrm{(3):} T=308.15 \mathrm{~K}$ and $P=0.1 \mathrm{MPa}$ (atmospheric pressure) ${ }^{1}$.

\begin{tabular}{cccccc}
\hline \multicolumn{2}{c}{ Surfactant Phase (Phase I) Mass Fraction } & \multicolumn{3}{c}{ Aqueous Phase (Phase $I I)$ Mass Fraction } \\
\hline $\boldsymbol{w}_{\mathbf{1}}$ & $\boldsymbol{w}_{\mathbf{2}}$ & $\boldsymbol{w}_{\mathbf{3}}$ & $\boldsymbol{w}_{\mathbf{1}}$ & $\boldsymbol{w}_{\mathbf{2}}$ & $\boldsymbol{w}_{\mathbf{3}}$ \\
\hline 0.0000 & 0.1561 & 0.8439 & 0.0000 & 0.9965 & 0.0035 \\
0.0265 & 0.2676 & 0.7059 & 0.0456 & 0.9481 & 0.0064 \\
0.1252 & 0.2748 & 0.5999 & 0.2051 & 0.7907 & 0.0041 \\
0.2594 & 0.3526 & 0.3880 & 0.3077 & 0.6900 & 0.0023 \\
0.2956 & 0.4366 & 0.2678 & 0.3265 & 0.6735 & 0.0000 \\
\hline
\end{tabular}

${ }^{1}$ Standard uncertainties $u$ are $u(T)=0.5 \mathrm{~K}, u(P)=10 \mathrm{kPa}, u_{\text {rel }}(w)=0.004$.

To further assess the capability of AE and to be able to compare it to others that have been considered as lactic acid extraction solvent, distribution coefficients, separation factors, and extraction efficiencies were estimated from the experimental tie-lines.

The distribution coefficients, $D_{i}$, and separation factors, $S$, of the LLE data for lactic acid $(i=1)$ and water $(i=2)$, and the lactic acid extraction efficiency, $E(\%)$, were calculated using the following equations [28,41]:

$$
\begin{gathered}
D_{i}=\frac{w_{i}^{I}}{w_{i}^{I I}}, \\
S=\frac{D_{1}}{D_{2}}, \\
E(\%)=\frac{D_{1}}{1+D_{1}} \times 100,
\end{gathered}
$$

where: $w_{1}^{I}$ and $w_{1}^{I I}$ are mass fractions of the lactic acid in the surfactant and aqueous phases, respectively, and; $w_{2}^{I}$ and $w_{2}^{I I}$ are mass fractions of water in surfactant and aqueous phases, respectively. The calculated values are presented in Table 3 and Figure 4.

Table 3. Distribution coefficients and separation factors for the ternary system containing lactic acid (1), water (2) and $\mathrm{AE} \mathrm{(3):} T=308.15 \mathrm{~K}, P=0.1 \mathrm{MPa}$ (atmospheric pressure).

\begin{tabular}{ccc}
\hline $\boldsymbol{D}_{\mathbf{1}}$ & $\boldsymbol{D}_{\mathbf{2}}$ & $\boldsymbol{S}$ \\
\hline 0.581 & 0.282 & 2.059 \\
0.610 & 0.348 & 1.756 \\
0.843 & 0.511 & 1.650 \\
0.905 & 0.648 & 1.397 \\
\hline
\end{tabular}




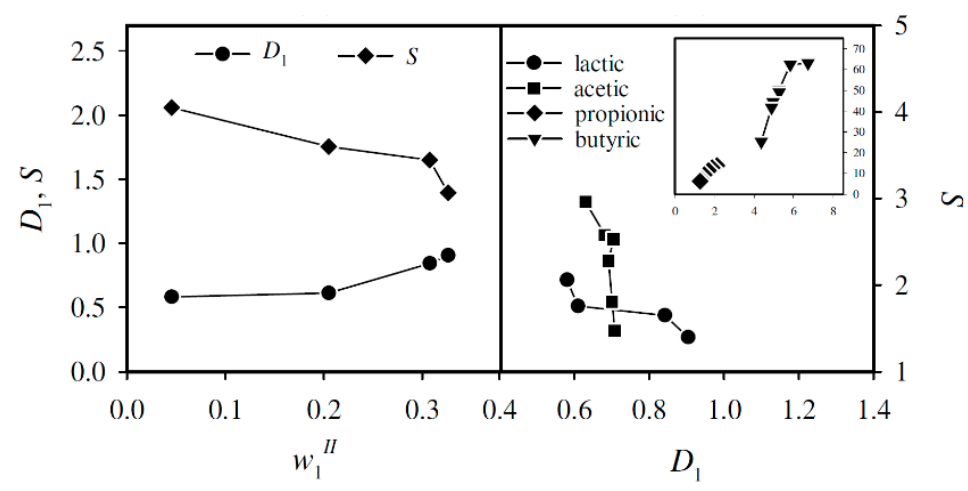

(a)

(b)

Figure 4. (a) Distribution coefficient, $D_{1}$, and separation factor, $S$, against the mass fraction of lactic acid in the aqueous phase at $T=308.15 \mathrm{~K}$ and $P=0.1 \mathrm{MPa}$ (atmospheric pressure); (b) $S$ as a function of $D_{1}$. Data for acetic, propionic, and butyric acids were calculated from Belgodere et al. [28].

The distribution coefficient, $D_{1}$, is an indication of the capacity of $\mathrm{AE}$ as a lactic acid extraction solvent [42]. For the liquid-liquid extraction process, higher values of $D_{1}$ are preferred to minimize the amount of solvent needed for extraction. Nevertheless, this is not the main requirement of an effective extraction process [43]. On the other hand, the separation factor or selectivity indicates the ability of a solvent to separate lactic acid from water [44] and can be viewed as an indicator of the number of extraction stages needed for extraction [42]. Similar to $D_{1}$, higher $S$ is also preferred for liquid-liquid extraction. The results showed that $D_{1}$ increases with lactic acid concentration in the aqueous phase while the trend is reverse for $S$ (Table 3 and Figure 4a). In relation to each other, $D_{1}$ is inversely proportional to $S$ (Figure $4 \mathrm{~b}$ ). This suggests that the extraction of lactic acid using AE will involve a balance or a compromise between the size of an extraction unit (which depends on amount of solvent) and the number of extraction units needed for the process. Lactic acid is chemically similar to propionic acid with respect to number of carbon atoms in its molecule. However, in terms of extractability with AE, lactic acid is similar to acetic acid (Figure $4 \mathrm{~b}$ ). This could be due to the presence of hydroxyl functional group in the lactic acid molecule, which makes it more hydrophilic compared to propionic acid.

Among the many solvents that have been considered for lactic acid extraction are those that are listed in Table 4. For the majority of the solvents, a diluent is necessary to improve $D_{1}$ and consequently $E(\%)$. Nevertheless, even for solvents that are utilized diluents, extraction efficiencies were not guaranteed as evident by $E(\%)$ values as low as $16.7 \%$. The highest efficiency obtained was $96.3 \%$, which uses an alamine 336-octanol solvent system for lactic acid extraction. The solvent considered in this study did not utilize any diluent and in terms of $E(\%)$, and is similar to tri- $n$-butyl phosphate with no diluent. The main difference, however, is the biodegradability and non-toxicity (to microbes) of $\mathrm{AE}$ which makes it a good candidate solvent for extractive lactic acid fermentation. According to Joglekar et al. [1], due to the toxicity of most solvents listed in Table 4, their application for extractive lactic acid fermentation will require the utilization of immobilized cells or enzyme systems. This can possibly be avoided by using AE as the extraction solvent. 
Table 4. Comparison of solvents for extraction of lactic acid from aqueous solution.

\begin{tabular}{|c|c|c|c|c|}
\hline Extractant ${ }^{1}$ & Diluent & $\begin{array}{c}\text { Distribution } \\
\text { Coefficient, } D_{1}\end{array}$ & $\begin{array}{c}\text { Extraction } \\
\text { Efficiency, } E(\%)\end{array}$ & Ref. \\
\hline MIBK & - & 0.13 & 11.5 & [45] \\
\hline TOA/methylene chloride & Chlorobenzene & 0.20 & 16.7 & [41] \\
\hline TBA & MIBK & 0.21 & 17.4 & [41] \\
\hline Alamine & Octanol & 0.62 & 38.3 & [1] \\
\hline $\mathrm{AE}$ & - & $0.58-0.91$ & $36.7-47.6$ & [This study] \\
\hline TBP & - & 0.95 & 48.8 & [41] \\
\hline TOA/TPA & - & 1.20 & 54.5 & [46] \\
\hline TOA & Chlorobutane & 1.40 & 58.3 & [47] \\
\hline TOA & $\begin{array}{c}\text { Methylene } \\
\text { chloride/n-hexane }\end{array}$ & 1.45 & 59.2 & [47] \\
\hline TOA/methylene chloride & Heptane & 2.14 & 68.2 & [41] \\
\hline TOPO & Xylene & 2.20 & 68.8 & [48] \\
\hline TOA/methylene chloride & Hexane & 2.52 & 71.6 & [41] \\
\hline Alamine 336 & Chloroform & 5.30 & 84.1 & [45] \\
\hline Alamine 336 & MIBK & 8.30 & 89.2 & [45] \\
\hline Trilauryl amine & Xylene & 8.30 & 89.2 & [45] \\
\hline TOA & Chloroform & 9.44 & 90.4 & [41] \\
\hline Alamine 336 & Oleyl alcohol & 13.00 & 92.9 & [49] \\
\hline Alamine 336 & Decanol & 23.37 & 95.9 & [50] \\
\hline Alamine 336 & Octanol & 25.95 & 96.3 & [51] \\
\hline
\end{tabular}

${ }^{1}$ MIBK-Methylisobutylketone, TOA-Tri- $n$-octylamine, TBA-Tributyl amine, TBP-Tri- $n$-butyl phosphate, TPA-Tripropylamine, TOPO-Trioctylphosphine oxide.

The relatively low extraction efficiency of AE could possibly have an effect on the economic feasibility of the separation process. There are however, other factors such as surfactant recycling, number of extraction stages, and fermentation mode (i.e., batch, semi-batch, and continuous) that need to be considered to evaluate the overall economic viability of the process. In a similar study by Belgodere [52], the economic assessment of the extraction of butyric acid using AE as solvent resulted in a payback period of 2.5 years, indicating the economic attractiveness of the process. For the case of lactic acid, further evaluation is needed to estimate the economic feasibility of the extraction process.

\subsection{Reliability of Tie-Line Data}

The obtained experimental tie-line data were tested for reliability using the Hand [53] (Equation (4)) and Bachman [54] (Equation (5)) correlations. These correlations are commonly used for consistency of phase equilibrium data [55-57]. The equations are obtained by:

$$
\begin{gathered}
\ln \left(\frac{w_{1}^{I I}}{w_{2}^{I I}}\right)=a+b \ln \left(\frac{w_{1}^{I}}{w_{3}^{I}}\right), \\
w_{1}^{I}=a^{\prime}+b^{\prime} \frac{w_{1}^{I}}{w_{2}^{I I}}
\end{gathered}
$$

where the subscripts of the mass fractions indicate the component (lactic acid $=1$, water $=2$, and $\mathrm{AE}=3$ ), the superscripts represent the phase (surfactant $=I$ and aqueous $=I I), a$ and $b$ are the parameters of the Hand correlation, and; $a^{\prime}$ and $b^{\prime}$ are the parameters of the Bachman correlation. The correlations plots including the parameters are presented in Figure 5. The linearity of the plots, as reflected in their correlation factors $\left(r^{2}\right)$ close to unity, indicates a high degree of reliability of the measured tie-line data. 


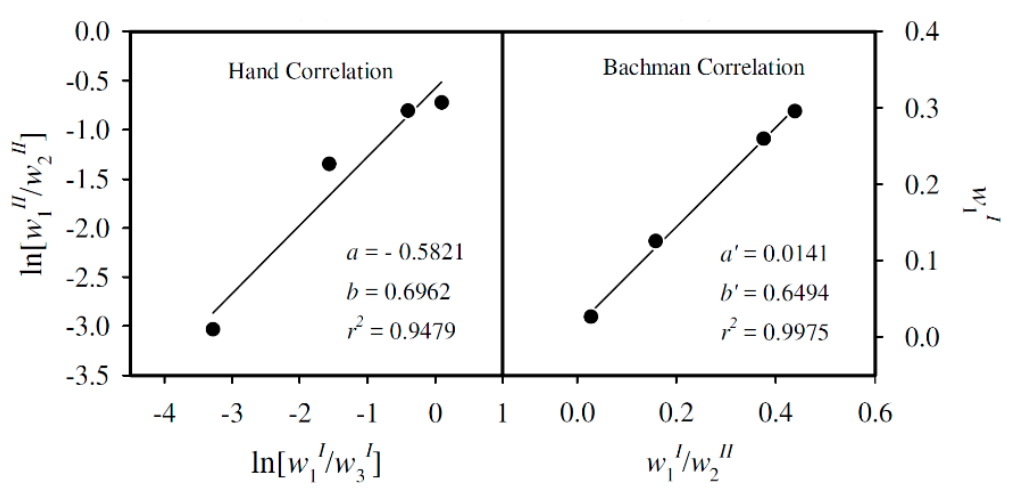

(a)

(b)

Figure 5. (a) Hand; and (b) Bachman correlation plots of the lactic acid + water + AE ternary system at $T=308.15 \mathrm{~K}$ and $P=0.1 \mathrm{MPa}$ (atmospheric pressure).

\section{Concluding Remarks}

This work was conducted with the goal of assessing non-ionic surfactants as potential solvents for extractive lactic acid fermentation. Compared to other solvents that have been evaluated for the targeted extraction process, non-ionic surfactants (particularly alcohol ethoxylates and alcohol alkoxylates) are known to be biodegradable and do not affect microbial activities. An initial assessment indicated that all the ternary systems containing lactic acid, water, and non-ionic surfactant are of the Type 1 (Treybal classification) ternary system with a water-surfactant binary pair exhibiting partial miscibility. In addition, the size of the phase envelope and stability of the phases formed suggested that the alcohol ethoxylate can possibly be utilized for the extraction process.

The phase diagram of the system containing lactic acid, water and alcohol ethoxylates was established at $308.15 \mathrm{~K}$. The estimated distribution coefficients and separation factors suggested that the use of alcohol ethoxylate as solvent for lactic acid extraction will involve a compromise between the size and number of extraction units needed for the operation. An extraction efficiency of 36.7-47.6\% was calculated, which is similar to that of tri- $n$-butyl phosphate. The reliability of the LLE data was tested using both Hand and Bachman correlations, showing satisfactory results.

This study presents the first attempt to utilize non-ionic surfactants as solvents for the separation of lactic acid from aqueous solutions. Although the obtained extraction efficiencies were not that high, AE with different alcohol lengths as well as different ethoxylate/propoxylate numbers and combinations can possibly be exploited for process improvement. The capacity of the surfactant to extract or solubilize lactic acid could be a combination of micelle formation, hydrogen bonding, or other interactions. The actual mechanism is out of the scope of this work. However, understanding the molecular interactions among lactic acid, surfactant and water could provide a deeper insight of the extraction phenomenon and will be the subject of further experimentation.

Author Contributions: Conceptualization, E.D.R., R.H., and M.E.Z.; Methodology and Investigation, R.A., W.H., S.L., C.S., S.B., and B.L.; Data curation, R.A. and E.D.R.; Writing-original draft preparation, R.A.; Writing-review and editing, E.D.R., R.H., and M.E.Z. All authors have read and agreed to the published version of the manuscript.

Funding: This research received no external funding.

Acknowledgments: This work was supported by the Energy Institute of Louisiana (EIL) and the University of Louisiana at Lafayette. Appreciation is felt toward the staff and undergraduate students of the EIL for their able assistance with the performance of this project.

Conflicts of Interest: The authors declare no conflict of interest. 


\section{References}

1. Joglekar, H.G.; Rahman, I.; Babu, S.; Kulkarni, B.D.; Joshi, A. Comparative Assessment of Downstream Processing Options for Lactic Acid. Sep. Purif. Technol. 2006, 52, 1-17. [CrossRef]

2. Komesu, A.; Wolf Maciel, M.R.; Maciel Filho, R. Separation and Purification Technologies for Lactic Acid-A Brief Review. BioResources 2017, 12, 6885-6901. [CrossRef]

3. Komesu, A.; Wolf Maciel, M.R.; Rocha de Oliveira, J.A.; da Silva Martins, L.H.; Maciel Filho, R. Purification of Lactic Acid Produced by Fermentation: Focus on Non-Traditional Distillation Processes. Sep. Purif. Rev. 2017, 46, 241-254. [CrossRef]

4. Schreurs, V.V.A.M.; Schaafsma, G. Lactic Acid and Lactates. Nutrafoods 2010, 9, 7-16. [CrossRef]

5. Cubas-Cano, E.; González-Fernández, C.; Ballesteros, M.; Tomás-Pejó, E. Biotechnological Advances in Lactic Acid Production by Lactic Acid Bacteria: Lignocellulose as Novel Substrate. Biofuel. Bioprod. Biorefin. 2018, 12, 290-303. [CrossRef]

6. Biddy, M.J.; Scarlata, C.; Kinchin, C. Chemicals from Biomass: A Market Assessment of Bioproducts with Near-Term Potential; NREL: Golden, CO, USA, 2016.

7. Alves de Oliveira, R.; Schneider, R.; Vaz Rossell, C.E.; Maciel Filho, R.; Venus, J. Polymer Grade L-Lactic Acid Production from Sugarcane Bagasse Hemicellulosic Hydrolysate Using Bacillus coagulans. Bioresour. Technol. Rep. 2019, 6, 26-31. [CrossRef]

8. Tu, W.-L.; Hsu, T.-C.; Wang, C.-A.; Guo, G.-L.; Chao, Y. Using Novel Lactobacillus plantarum to Produce Lactic Acid from Lignocellulosic Biomass in an Integrated Simultaneous Saccharification and Fermentation Process. BioResources 2019, 14, 3873-3885.

9. Berlowska, J.; Cieciura, W.; Borowski, S.; Dudkiewicz, M.; Binczarski, M.; Witonska, I.; Otlewska, A.; Kregiel, D. Simultaneous Saccharification and Fermentation of Sugar Beet Pulp with Mixed Bacterial Cultures for Lactic Acid and Propylene Glycol Production. Molecules 2016, 21, 1380. [CrossRef] [PubMed]

10. Othman, M.; Ariff, A.B.; Rios-Solis, L.; Halim, M. Extractive Fermentation of Lactic Acid in Lactic Acid Bacteria Cultivation: A Review. Front. Microbiol. 2017, 8. [CrossRef] [PubMed]

11. Song, J.-Y.; Park, J.-S.; Kang, C.D.; Cho, H.-Y.; Yang, D.; Lee, S.; Cho, K.M. Introduction of a Bacterial Acetyl-CoA Synthesis Pathway Improves Lactic Acid Production in Saccharomyces cerevisiae. Metab. Eng. 2016, 35, 38-45. [CrossRef] [PubMed]

12. Baek, S.-H.; Kwon, E.Y.; Bae, S.-J.; Cho, B.-R.; Kim, S.-Y.; Hahn, J.-S. Improvement of D-Lactic Acid Production in Saccharomyces cerevisiae under Acidic Conditions by Evolutionary and Rational Metabolic Engineering. Biotechnol. J. 2017, 12, 1700015. [CrossRef] [PubMed]

13. Upadhyaya, B.P.; DeVeaux, L.C.; Christopher, L.P. Metabolic Engineering as a Tool for Enhanced Lactic Acid Production. Trends Biotechnol. 2014, 32, 637-644. [CrossRef] [PubMed]

14. Eş, I.; Mousavi Khaneghah, A.; Barba, F.J.; Saraiva, J.A.; Sant Ana, A.S.; Hashemi, S.M.B. Recent Advancements in Lactic Acid Production-A Review. Food Res. Int. 2018, 107, 763-770. [CrossRef] [PubMed]

15. Mears, L.; Stocks, S.M.; Sin, G.; Gernaey, K.V. A Review of Control Strategies for Manipulating the Feed Rate in Fed-Batch Fermentation Processes. J. Biotechnol. 2017, 245, 34-46. [CrossRef] [PubMed]

16. Ÿztürk, S.; ÿalık, P.; ÿzdamar, T.H. Fed-Batch Biomolecule Production by Bacillus subtilis: A State of the Art Review. Trends Biotechnol. 2016, 34, 329-345. [CrossRef]

17. Aso, Y.; Tsubaki, M.; Dang Long, B.H.; Murakami, R.; Nagata, K.; Okano, H.; Phuong Dung, N.T.; Ohara, H. Continuous Production of D-Lactic Acid from Cellobiose in Cell Recycle Fermentation Using B-Glucosidase-Displaying Escherichia coli. J. Biosci. Bioeng. 2019, 127, 441-446. [CrossRef]

18. Gao, M.-T.; Shimamura, T.; Ishida, N.; Nagamori, E.; Takahashi, H.; Umemoto, S.; Omasa, T.; Ohtake, H. Extractive Lactic Acid Fermentation with Tri-N-Decylamine as the Extractant. Enzym. Microb. Technol. 2009, 44, 350-354. [CrossRef]

19. Boonmee, M.; Cotano, O.; Amnuaypanich, S.; Grisadanurak, N. Improved Lactic Acid Production by in Situ Removal of Lactic Acid During Fermentation and a Proposed Scheme for Its Recovery. Arab. J. Sci. Eng. 2016, 41, 2067-2075. [CrossRef]

20. Yuwono, S.D.; Mulyono, M.; Buhani, B.; Suharso, S.; Sukmana, I. Purification of Lactic Acid from Cassava Bagasse Fermentation Using Ion Exchange. ARPN J. Eng. Appl. Sci. 2017, 12, 3853-3857. 
21. Min-tian, G.; Koide, M.; Gotou, R.; Takanashi, H.; Hirata, M.; Hano, T. Development of a Continuous Electrodialysis Fermentation System for Production of Lactic Acid by Lactobacillus rhamnosus. Process. Biochem. 2005, 40, 1033-1036. [CrossRef]

22. Fan, R.; Ebrahimi, M.; Czermak, P. Anaerobic Membrane Bioreactor for Continuous Lactic Acid Fermentation. Membranes 2017, 7, 26. [CrossRef] [PubMed]

23. Kuznetsov, A.; Beloded, A.; Derunets, A.; Grosheva, V.; Vakar, L.; Kozlovskiy, R.; Shvets, V. Biosynthesis of Lactic Acid in a Membrane Bioreactor for Cleaner Technology of Polylactide Production. Clean Technol. Environ. 2017, 19, 869-882. [CrossRef]

24. Wasewar, K.L.; Yawalkar, A.A.; Moulijn, J.A.; Pangarkar, V.G. Fermentation of Glucose to Lactic Acid Coupled with Reactive Extraction: A Review. Ind. Eng. Chem. Res. 2004, 43, 5969-5982. [CrossRef]

25. Brink, L.E.S.; Tramper, J. Optimization of Organic Solvent in Multiphase Biocatalysis. Biotechnol. Bioeng. 1985, 27, 1258-1269. [CrossRef]

26. Merrettig-Bruns, U.; Jelen, E. Anaerobic Biodegradation of Detergent Surfactants. Materials 2009, 2, $181-206$. [CrossRef]

27. Elsamadony, M.; Tawfik, A.; Suzuki, M. Surfactant-Enhanced Biohydrogen Production from Organic Fraction of Municipal Solid Waste (OFMSW) via Dry Anaerobic Digestion. Appl. Energy 2015, 149, 272-282. [CrossRef]

28. Belgodere, J.A.; Revellame, E.D.; Hernandez, R.; Holmes, W.; Collazos, L.; Bajpai, R.; Zappi, M.E. Liquid-Liquid Equilibria for (Volatile Fatty Acids + Water + Alcohol Ethoxylates): Experimental Measurement of Pseudo-Ternary Systems. J. Chem. Thermodyn. 2019, 128, 207-214. [CrossRef]

29. Dhamole, P.B.; Wang, Z.; Liu, Y.; Wang, B.; Feng, H. Extractive Fermentation with Non-Ionic Surfactants to Enhance Butanol Production. Biomass Bioenergy 2012, 40, 112-119. [CrossRef]

30. Kravetz, L.; Chung, H.; Rapean, J.C.; Guin, K.F.; Shebs, W.T. Ultimate Biodegradability of Detergent Range Alcohol Ethoxylates. In Proceedings of the 69th Annual Meeting of the American Oil Chemists' Society, St. Louis, MO, USA, 15 May 1978.

31. Balson, T.; Felix, M.S.B. Biodegradability of Non-Ionic Surfactants. In Biodegradability of Surfactants; Karsa, D.R., Porter, M.R., Eds.; Springer: Dordrecht, The Netherlands, 1995; pp. 204-230. [CrossRef]

32. Bhairi, S.M.; Mohan, C. Detergents. A Guide to the Properties and Uses of Detergents in Biological Systems. Ph.D. Thesis, Calbiochem®, EMD Biosciences, San Diego, CA, USA, 1999.

33. ICI Americas Inc. The HLB System a Time-Saving Guide to Emulsifier Selection; ICI Americas Inc.: Delaware, DE, USA, 1980.

34. Rang, M.J.; Miller, C.A. Spontaneous Emulsification of Oils Containing Hydrocarbon, Nonionic Surfactant, and Oleyl Alcohol. J. Colloid Inter. Sci. 1999, 209, 179-192. [CrossRef]

35. Gomis, A.M.; Reyes-Labarta, J.A.; Cayuelas, M.D.S.; López, M.d.M.O. Ge Models and Algorithms for Condensed Phase Equilibrium Data Regression in Ternary Systems: Limitations and Proposals. Open Thermodyn. J. 2011, 5, 48-62. [CrossRef]

36. Broze, G. Phase Equilibria. In Liquid Detergents, 2nd ed.; Lai, K.-Y., Ed.; CRC Press: Boca Raton, FL, USA, 2005; pp. 39-72. [CrossRef]

37. Centre for Industry Education Collaboration. Surfactants. Available online: https://www.mcpolymers.com/ library/whats-in-a-can-a-chat-with-solvay-about-surfactants (accessed on 6 January 2020).

38. Al-Sabagh, A.M.; Nasser, N.M.; Migahed, M.A.; Kandil, N.G. Effect of Chemical Structure on the Cloud Point of Some New Non-Ionic Surfactants Based on Bisphenol in Relation to Their Surface Active Properties. Egypt. J. Pet. 2011, 20, 59-66. [CrossRef]

39. Ghouas, H.; Haddou, B.; Kameche, M.; Canselier, J.P.; Gourdon, C. Removal of Tannic Acid from Aqueous Solution by Cloud Point Extraction and Investigation of Surfactant Regeneration by Microemulsion Extraction. J. Surfactants Deterg. 2016, 19, 57-66. [CrossRef]

40. Goodner, K.L. Estimating Turbidity (NTU) from Absorption Data. Ph.D. Thesis, LLC, Synergy Flavors, OH, USA, 2009.

41. Han, D.H.; Hong, Y.K.; Hong, W.H. Separation Characteristics of Lactic Acid in Reactive Extraction and Stripping. Korean J. Chem. Eng. 2000, 17, 528-533. [CrossRef]

42. Richard, R.; Ferrando, N.; Jacquin, M. Liquid-Liquid Equilibria for Ternary Systems Acetic Acid + N-Butyl Acetate + Hydrocarbons at 293.15 K. Fluid Phase Equilibr. 2013, 356, 264-270. [CrossRef]

43. Thakore, S.B.; Bhatt, B.I. Introduction to Process. Engineering and Design; Tata McGraw-Hill Publishing Company Limited: New Delhi, India, 2007. 
44. Bayazıt, K.; Gök, A.; Uslu, H.; Kırbaşlar, Ş.İ. Phase Equilibria of (Water + Butyric Acid + Butyl Acetate) Ternary Systems at Different Temperatures. Fluid Phase Equilibr. 2014, 379, 185-190. [CrossRef]

45. Tamada, J.A.; King, C.J. Extraction of Carboxylic Acids with Amine Extractants. 2. Chemical Interactions and Interpretation of Data. Ind. Eng. Chem. Res. 1990, 29, 1327-1333. [CrossRef]

46. Hong, Y.K.; Hong, W.H. Reactive Extraction of Lactic Acid with Mixed Tertiary Amine Extractants. Biotechnol. Tech. 1999, 13, 915-918. [CrossRef]

47. Han, D.H.; Hong, W.H. Water-Enhanced Solubilities of Lactic Acid in Reactive Extraction Using Trioctylamine/Various Active Diluents Systems. Sep. Sci. Technol. 1998, 33, 271-281. [CrossRef]

48. von Frieling, P.; Schügerl, K. Recovery of Lactic Acid from Aqueous Model Solutions and Fermentation Broths. Process. Biochem. 1999, 34, 685-696. [CrossRef]

49. Inci, I.; Aydin, A. Extraction of Hydroxycarboxylic Acids with MIBK/Toluene Solutions of Amines. J. Sci. Ind. Res. 2003, 62, 926-930.

50. Wasewar, K.L.; Heesink, A.B.M.; Versteeg, G.F.; Pangarkar, V.G. Equilibria and Kinetics for Reactive Extraction of Lactic Acid Using Alamine 336 in Decanol. J. Chem. Technol. Biotechnol. 2002, 77, 1068-1075. [CrossRef]

51. Wasewar, K.L.; Pangarkar, V.G.; Heesink, A.B.M.; Versteeg, G.F. Intensification of Enzymatic Conversion of Glucose to Lactic Acid by Reactive Extraction. Chem. Eng. Sci. 2003, 58, 3385-3393. [CrossRef]

52. Belgodere, J.A. Liquid-Liquid Extraction of Volatile Organic Acids Using Specialty Surfactants. Master's Thesis, University of Louisiana at Lafayette, Lafayette, LA, USA, 2016.

53. Hand, D.B. Dineric Distribution. J. Phys. Chem. 1929, 34, 1961-2000. [CrossRef]

54. Bachman, I. Tie Lines in Ternary Liquid Systems. Ind. Eng. Chem. Anal. Ed. 1940, 12, 38-39. [CrossRef]

55. Liu, X.; Xu, D.; Diao, B.; Gao, J.; Zhang, L.; Ma, Y.; Wang, Y. Separation of Dimethyl Carbonate and Methanol by Deep Eutectic Solvents: Liquid-Liquid Equilibrium Measurements and Thermodynamic Modeling. J. Chem. Eng. Data 2018, 63, 1234-1239. [CrossRef]

56. Xu, D.; Zhang, L.; Gao, J.; Pratik, D.; Zhao, L.; Cui, Z. Liquid-Liquid Equilibrium for Ternary Systems of Ethyl Acetate/Isopropyl Acetate + 2,2,3,3-Tetrafluoro-1-Propanol + Water at 298.15, 318.15 K. J. Chem. Thermodyn. 2017, 106, 218-227. [CrossRef]

57. Xu, D.; Zhang, L.; Gao, J.; Zhang, Z.; Cui, Z. Measurement and Correlation of Liquid-Liquid Equilibrium for the Ternary System 2,2,3,3,4,4,5,5-Octafluoro-1-Pentanol + Methanol + water at $(298.15,308.15$, and 318.15) K. Fluid Phase Equilibr. 2016, 409, 377-382. [CrossRef] 